\title{
Depth of origin of magma in eruptions
}

\author{
Laura Becerril' ', Ines Galindo', Agust Gudmundsson² \& Jose Maria Morales'
}

SUBJECT AREAS:

SEISMOLOGY

VOLCANOLOGY

${ }^{1}$ Spanish Geological Survey (IGME), Unit of Canary Islands, Alonso Alvarado, 43, $2{ }^{\circ}$ A, Las Palmas, 35003, Spain, ${ }^{2}$ Department of Earth Sciences, University of London Royal Holloway, Egham TW20 OEX, UK.

STRUCTURAL GEOLOGY

GEODYNAMICS

Received

8 April 2013

Accepted

4 September 2013

Published

26 September 2013

Correspondence and requests for materials should be addressed to I.G. (i.galindo@igme.

Many volcanic hazard factors - such as the likelihood and duration of an eruption, the eruption style, and the probability of its triggering large landslides or caldera collapses - relate to the depth of the magma source. Yet, the magma source depths are commonly poorly known, even in frequently erupting volcanoes such as Hekla in Iceland and Etna in Italy. Here we show how the length-thickness ratios of feeder dykes can be used to estimate the depth to the source magma chamber. Using this method, accurately measured volcanic fissures/feeder-dykes in El Hierro (Canary Islands) indicate a source depth of 11-15 km, which coincides with the main cloud of earthquake foci surrounding the magma chamber associated with the 2011-2012 eruption of El Hierro. The method can be used on widely available GPS and InSAR data to calculate the depths to the source magma chambers of active volcanoes worldwide.

\section{A} fter decades of research and greatly improved volcano monitoring technology ${ }^{1-3}$, the depth of origin of magma in most eruptions is still poorly constrained. The depth to the source magma chamber affects many hazard and risk factors such as the likelihood of an injected dyke reaching the surface (the probability of an eruption), the dyke driving pressure, the magma viscosity, the volumetric flow rate and likely size and duration of the eruption, and the probability of lateral (landslide) and vertical (caldera) collapses ${ }^{4-6}$.

Most volcanic eruptions are supplied with magma through dykes ${ }^{4-8}$. Most feeder-dykes, in turn, are injected from magma chambers ${ }^{4-6}$. A magma chamber may be defined as a partially or totally molten body located in the earth's crust and capable of supplying magma to volcanic eruptions ${ }^{4-6}$. An active magma chamber acts as a sink for magma from a deeper reservoir, which is commonly located in the lower crust or the upper mantle. By contrast, the chamber acts as a source for magma injections (dykes, sheets, sills) into the surrounding crust and to the surface of the associated volcano. The geometries of magma chambers vary. Many chambers are sill-like, that is, similar to flat oblate ellipsoids ${ }^{4}$. Others, however, develop geometries that are closer to being approximately spherical, and occasionally, prolate ellipsoidal.

Some chambers, in particular young chambers with sill-like geometries, may be totally molten ${ }^{4}$. By contrast, many chambers are partially molten from soon after their initiation. Commonly, the greater part of the chamber then consists of a crystal mush, a matrix, which behaves as poroelastic media, with only the central or upper part of the chamber totally molten. At high strain rates, such as during earthquakes, parts of the matrix may fail in a brittle manner. Many, perhaps most, volcanoes are fed by double magma chambers ${ }^{4,5}$. The upper chamber is then referred to as the 'shallow' chamber, even if it may be at a considerable crustal depth, and the lower chamber is referred to as the reservoir. The shallow chamber acts as a collector of magma from the deeper source reservoir and channels that magma to a limited area at the surface above the chamber where the volcano or, as in the present case, a part or the whole of a volcanic island, builds up.

Many plutons have been identified as fossil shallow magma chambers in that their exposed roofs are dissected by dykes ${ }^{4}$. Based on analogies with active volcanoes ${ }^{4-6}$, some of the injected dykes are likely to have reached the surface to feed eruptions. For many of the fossil chambers, the depths of their uppermost parts can be inferred from the related stratigraphy and volcanotectonic considerations. These considerations indicate that some fossil roofs are exposed at depths of 1-2 km below the initial surfaces of the associated volcanic edifices ${ }^{4}$.

Magma chambers in major stratovolcanoes, calderas, and basaltic edifices are commonly active for hundreds of thousands of years. Active chambers may be partly or totally destroyed through large collapse-caldera eruptions ${ }^{9-12}$. Following the destruction of a chamber, a new chamber sometimes forms to the side of the destroyed one ${ }^{9,11}$. The new chamber may be either deeper or shallower than the previous one, with associated changes in eruption style.

Many petrological, geochemical, and geophysical methods have been used to infer the depths to the source chambers of feeder-dykes. The uncertainty in the depth estimates is normally in the order of several kilometres. Even in many highly active and well-monitored volcanoes, such as Etna (Italy) and Hekla (Iceland), the magmachamber depths are poorly constrained. The most widely used methods for this purpose are inversion of geodetic 


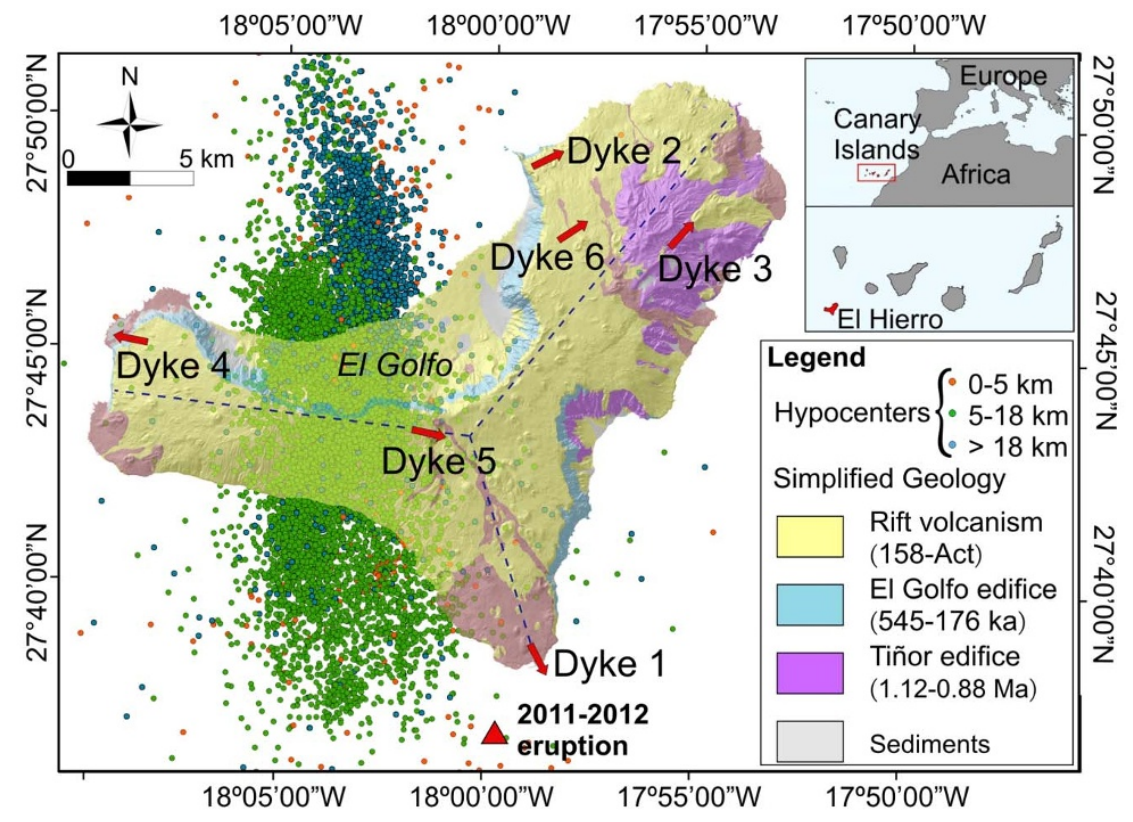

Figure 1 Location and a schematic geological map of El Hierro. The six feeder-dykes discussed here are represented by red arrows, indicating also the possible direction of magma flow from a chamber whose location coincides roughly with that of the chamber active in the 2011-2012 eruption (as indicated primarily by the hypocentres at 5-18 km depth). The site of the 2011-2012 eruption is indicated by a red, filled triangle. Dashed blue lines indicate three main rifts axes. Data on hypocentres, registered from 19 July 2011 to 5 March 2012, are open-source data from the IGN Seismic Catalogue, the address of the webpage being: http://www.ign.es/ign/layoutIn/volcaFormularioCatalogo.do (cf. ref. 36). Map composed in ESRI ArcGIS 9.3.1.

and seismic data. These methods have been applied only in the past decades and thus cannot be used to trace the magma-chamber location/depth evolution over periods of thousands or tens of thousands of years.

The depth of origin of the magma in the eruptions is here regarded as the depth to the intersection between the feeder-dyke and its source chamber. While volcanic fissures are very common, their feeder-dykes have so far been rarely reported. For example, in Iceland and Tenerife (Canary Islands), with hundreds of volcanic fissures and tens of thousands of measured dykes, only 11 clear-cut young feeder-dykes have been identified ${ }^{6}$. In comparison with the number of observed dykes worldwide, reported feeder-dykes are rare $^{4-8}$. The six well-exposed feeder-dykes in El Hierro, all from the same (comparatively small) volcanic field and (mostly) in a rather narrow age range, provide therefore an excellent set of dykes for testing the present method (Fig. 1).

Here we develop a method for estimating the depth to the source magma chamber, that is, the intersection between the feeder and the chamber, from the length-thickness (aspect) ratios of volcanic fissures/ feeder-dykes. The method uses the overpressure of the magma in the feeder-dyke close to or at the surface to estimate the depth to its source magma chamber. The overpressure is obtained from the ratio between the strike dimension (surface length) and the thickness of the feederdyke close to or at the surface. All the dykes are basaltic in composition.

There are two factors that could potentially affect the estimated aspect ratios through changes in the feeder-dyke thickness as the eruption gradually comes to an end. One is the possible decrease in the dyke opening (thickness) as the overpressure decreases towards the end of the eruption. The other is dyke-volume decrease during dyke-magma solidification. Field observations indicate that the first factor rarely (if ever) happens. First, field studies show that most feeder-dykes have much greater openings, are thicker, close to the surface than at greater depths. This thickness increase may be partly attributed to magma-erosion effects, but is mainly because of free-surface effects ${ }^{6,7}$. To minimise the effects of thickness increase very close to and at the surface, we made our feeder-dyke thickness measurements some distance below the surface.
Second, there are also mechanical reasons indicating that the near surface parts of a feeder-dyke (where the thickness measurements are made) are unlikely to reduce their thickness as a result of magmatic overpressure decrease towards the end of the eruption. The nearsurface parts of a feeder-dyke solidify partly during the eruption. Commonly, scoria and/or spatter gradually fill part of the dyke opening as the eruption progresses and lava flow/crater cones straddle the dyke-opening itself. The bottom part of the lava flow has already solidified before the end of the eruption and the high-friction solid-solid contact between the new lava flow and the host rock (onto which the new lava erupts) effectively clamps the feeder-dyke (fig. 3C in ref. 6). This means that the opening of the near-surface part of a feeder-dyke normally becomes essentially fixed early on in the eruption and is generally maintained except for the effects of general dyke solidification, which are, for the reasons given above, less noticeable in the near-surface part of the feeder-dyke than in its deeper parts.

The effects of the second factor, namely general solidification of the feeder-dyke, are well known. On solidification basaltic magma decreases its volume by about $10 \%$ (a factor of 0.1 ) or less, as is evident from comparing the typical densities of liquid and solid basalt $^{4-8}$. A factor of 0.1 is entirely insignificant in the present calculations, and the feeder-dyke aspect ratios may be regarded as reliable data for the magma-chamber depth estimates.

Using new field data on feeder-dyke thicknesses and volcanicfissure lengths in El Hierro (Canary Islands), the present method is used to determine the depth to the source magma chambers for six feeder-dykes. The results are compared with the estimated depth (from earthquake foci) of the main source magma chamber of the 2011-2012 eruption of El Hierro. We then discuss how the method can be applied to volcanoes worldwide, using GPS and InSAR data, thereby putting new constraints on the depths of source magma chambers in active volcanoes.

\section{Results}

We apply the present method (cf. the section on 'Methods' below) to a set of carefully measured feeder-dykes in El Hierro (Canary 
Islands). Based on geological mapping ${ }^{13}$, most of the feeder-dykes are $2-160 \mathrm{ka}$ old. The results show that the estimated depths to the main source chamber are mostly between $11 \mathrm{~km}$ and $15 \mathrm{~km}$, similar to the depth to Moho. For comparison, the cloud of earthquake foci associated with the 2011-2012 eruption in El Hierro is at the depth of 8$16 \mathrm{~km}$, indicating that the presently active 'shallow' chamber is at a depth very similar to the source depths of the feeder-dykes. With widely available GPS/InSAR data on length-opening ratios of volcanic fissures, this method can be used to determine the depths to magma chambers in active volcanoes worldwide. Furthermore, measurements of well-exposed feeder-dykes in the same volcanoes make it possible to trace the long-term evolution of the magma-chamber depth.

When the aspect ratios of feeder-dykes are known, the method developed here can be used to estimate the depth of magma chambers that are currently active, as well as those that were active thousands or tens of thousands of years ago (cf. the section on Methods below). The detailed variations in the aperture of a volcanic fissure/ thickness of a feeder-dyke can be modelled using Fourier cosine series ${ }^{14}$ or polynomials ${ }^{15}$. Commonly, however, the detailed variation in aperture/thickness is not known but rather the opening/thickness at a single site or, at most, a few sites ${ }^{6-8}$. Then the following method can be used to estimate the depth to the source chamber. The opening displacement $\Delta u_{I}$ of an elastic mode I (tensile mode) crack subject to internal fluid overpressure $p_{o}$ is given by ${ }^{15,16}$

$$
\Delta u_{I}=\frac{2 p_{o}\left(1-v^{2}\right) L}{E}
$$

where $L$ is the smaller of the strike and dip dimensions of the fracture, and $E$ and $v$ are Young's modulus and Poisson's ratio, respectively, of the host rock. This equation applies strictly only to the maximum opening. However, many dykes show comparatively smooth flatelliptical variations in their openings/displacements, in which case the maximum displacement is similar to the average displacement ${ }^{7,8,14,15}$. The overpressure in the dyke at the surface is given by ${ }^{15}$

$$
p_{o}=p_{e}+\left(\rho_{r}-\rho_{m}\right) g h+\sigma_{d}
$$

where $p_{\mathrm{e}}$ is the fluid excess pressure in the source magma chamber, $\rho_{\mathrm{r}}$ is the average density of the host rock, $\rho_{\mathrm{m}}$ is the average density of the magma in the dyke, $g$ is acceleration due to gravity, $h$ is the depth to the source chamber, and $\sigma_{\mathrm{d}}$ is the differential stress (the difference between the vertical stress and the minimum principal horizontal stress) at the surface where the volcanic fissure forms.

These equations can be combined and solved for the depth to the intersection between the source magma chamber and the feederdyke thus

$$
h=\frac{\Delta u_{I} E}{2 L\left(1-v^{2}\right)\left(\rho_{r}-\rho_{m}\right) g}-\frac{p_{e}+\sigma_{d}}{\left(\rho_{r}-\rho_{m}\right) g}
$$

where all the symbols are as defined above.

Using Eq. (3), we calculated the depth to the source chambers of six feeder-dykes exposed in El Hierro (Fig. 1). We use the typical basaltic magma density of $2650 \mathrm{~kg} \mathrm{~m}^{-317}$. There are no detailed and accurate density data on the crust of El Hierro; it is mostly thought to be composed of pyroclastic rocks, pillow basalt, massive basalt, and gabbros in an estimated density range of $2300-3100 \mathrm{~kg} \mathrm{~m}^{-318,19}$. We use an average density of $2750 \mathrm{~kg} \mathrm{~m}^{-3}$, which is also similar to that of the uppermost $10 \mathrm{~km}$ of the rift zone in Iceland ${ }^{20}$. The excess pressure $p_{\mathrm{e}}$ in the magma chamber before rupture and dyke injection is taken as the typical in-situ tensile strength of $2.5 \mathrm{MPa}^{15}$. At the Earth's surface the vertical stress is atmospheric $(0.1 \mathrm{MPa})$, so that $\sigma_{\mathrm{d}}$ is effectively the in-situ tensile stress at failure in the fractured and weak surface layer, here taken as $1 \mathrm{MPa}^{15}$. The Young's modulus $(5 \mathrm{GPa})$ and Poisson's ratio (0.25) used are typical near-surface riftzone values $^{15,20}$.

The surface lengths of the dykes range from 75 to $535 \mathrm{~m}$. Some of the dykes used here form parts of longer fissures of offset and underlapping segments ${ }^{15}$. When the nearby tips of the segments are very close in relation to the segment lengths, particularly when the segments are collinear (no lateral offsets), the entire length of the fissure/dyke should be used when calculating the (aspect) ratio L/ $\Delta u_{I}$ in Eq. (1). However, when, like here, the segments have (commonly large) underlaps and offsets, the length of the fissure/dyke segment where the opening/thickness is measured should be used for calculating the aspect ratio. This follows because when the distance between segments increases (in relation to the segment lengths), their opening displacements become less and less affected by the nearby segments ${ }^{15,16}$.

The feeder-dyke thicknesses range from 0.33 to $1.33 \mathrm{~m}$, and the estimated overpressures from Eq. (1) are from 11 to $18 \mathrm{MPa}$. Using these and the above values, Eq. (3) yields source-chamber depths of 11-15 km (Table 1), except for Dyke $1(8 \mathrm{~km})$. On comparison with the depths of the earthquake foci associated with the pressure change in the assumed main magma chamber that supplied magma during the 2011-2012 El Hierro eruption, the feeder-dykes have generally a very similar source depth as the magma chamber (Fig. 2). For comparison, the high-density cloud of earthquake foci prior to and during the 2011-2012 El Hierro eruption, assumed to be the approximate location of the magma chamber, is at $8-16 \mathrm{~km}$ depth.

We divide the earthquakes into three main groups according to depth of foci (Figs. $1 \& 2$ ). The first group includes earthquakes at 0 $5 \mathrm{~km}$ depth. These earthquakes are mostly related to magma movement in connection with the eruption itself; many occur at the eruption site (Fig. 2A). The second group includes earthquakes at $5-18 \mathrm{~km}$ depth, mostly $8-16 \mathrm{~km}$, and indicates crudely the region hosting the 'shallow' magma chamber. The third group contains earthquakes deeper than $18 \mathrm{~km}$ depth, mostly at $18-23 \mathrm{~km}$, and outlines the region hosting a deeper magma chamber (or reservoir).

The shallow chamber is most likely partially molten ${ }^{4}$, so that some of the earthquakes may occur inside the crystalline matrix of the chamber itself. This follows because at the high strain rates associating with earthquake-fracture propagation, part of the crystalline matrix may behave as brittle. Most of the earthquakes, however, are likely to occur in the host rock in response to magma-pressure

Table 1 | Data for the depth of origin calculations of the six feeder-dykes. In these calculations, based on Eqs. (1-3), the excess pressure in the chamber before dyke injection $\left(\mathrm{p}_{\mathrm{e}}\right)$ is taken as $2.5 \mathrm{MPa}$ (a typical crustal tensile strength), the acceleration due to gravity is $9.81 \mathrm{~ms}^{-1}$, and

\begin{tabular}{|c|c|c|c|c|c|}
\hline Dyke & Strike & Thickness $\Delta \mathrm{v}_{l}(\mathrm{~m})$ & Length $L(\mathrm{~m})$ & Overpressure $p_{0}(\mathrm{MPa})$ & Depth $h(\mathrm{~km})$ \\
\hline $\begin{array}{l}\text { Dyke } 1 \\
\text { Dyke } 2 \\
\text { Dyke } 3 \\
\text { Dyke } 4 \\
\text { Dyke } 5 \\
\text { Dyke } 6\end{array}$ & $\begin{array}{r}155^{\circ} \\
66^{\circ} \\
44^{\circ} \\
103^{\circ} \\
104^{\circ} \\
57^{\circ}\end{array}$ & $\begin{array}{l}0.33 \\
0.6 \\
3 \\
1.2 \\
0.78 \\
1.33\end{array}$ & $\begin{array}{r}75 \\
105 \\
535 \\
190 \\
110 \\
200\end{array}$ & $\begin{array}{l}12 \\
15 \\
15 \\
17 \\
11 \\
18\end{array}$ & $\begin{array}{r}8 \\
12 \\
11 \\
13 \\
15 \\
14\end{array}$ \\
\hline
\end{tabular}
the stress difference at the fractured surface $\left(\sigma_{d}\right)$ is taken as $1 \mathrm{MPa}$. The columns are as follows: Strike of dyke, thickness of dyke $\left(\Delta u_{l}\right)$, length of dyke (L), calculated magma overpressure in dyke $\left(p_{0}\right)$, and calculated depth of origin of dyke $(h)$ 
changes in the chamber. The pressure-induced stresses fall off with distance from the chamber - for example, with the cube and square of the distance from spherical and cylindrical chambers, respectively ${ }^{15}$. Thus, much of the earthquake activity is likely to be comparatively close to the magma-pressure source, that is, the fluid part of the chamber. Based on this, and the density of the earthquake foci (Fig. 2), the present fluid part of the shallow chamber may be at depth of around 10-14 km. On this assumption, the depth of origin of most of the feeder-dykes would coincide with the estimated depth of the (roof of the) presently active shallow magma chamber beneath El Hierro (Fig. 2). This is also roughly the depth of Moho beneath El Hierro $^{18,19}$, a major discontinuity likely to encourage sill emplacement and magma-chamber formation ${ }^{4}$.
The feeder-dykes have a radial arrangement with respect to the location of the main clouds of earthquake foci which we interpret as being approximately the locations of the presently active shallow and deep magma chambers (Fig. 1). Theoretically, all the feeders could therefore have been injected from the present magma chambers. If they were injected from the shallow chamber, $10-15 \mathrm{~km}$ of vertical and 3-17 km of lateral propagation would be needed to reach their current locations. All the dykes except one have estimated ages between $2 \mathrm{ka}$ and $160 \mathrm{ka}$ (Dyke 3 has an estimated age of less than $1 \mathrm{Ma}$ ). Based on the trends of the dykes, and their ages, the results indicate that all the dykes (except Dyke 3) could have come from a magma chamber located at roughly the same location as the present shallow chamber, which might then have been active for the past 100-200 ka.
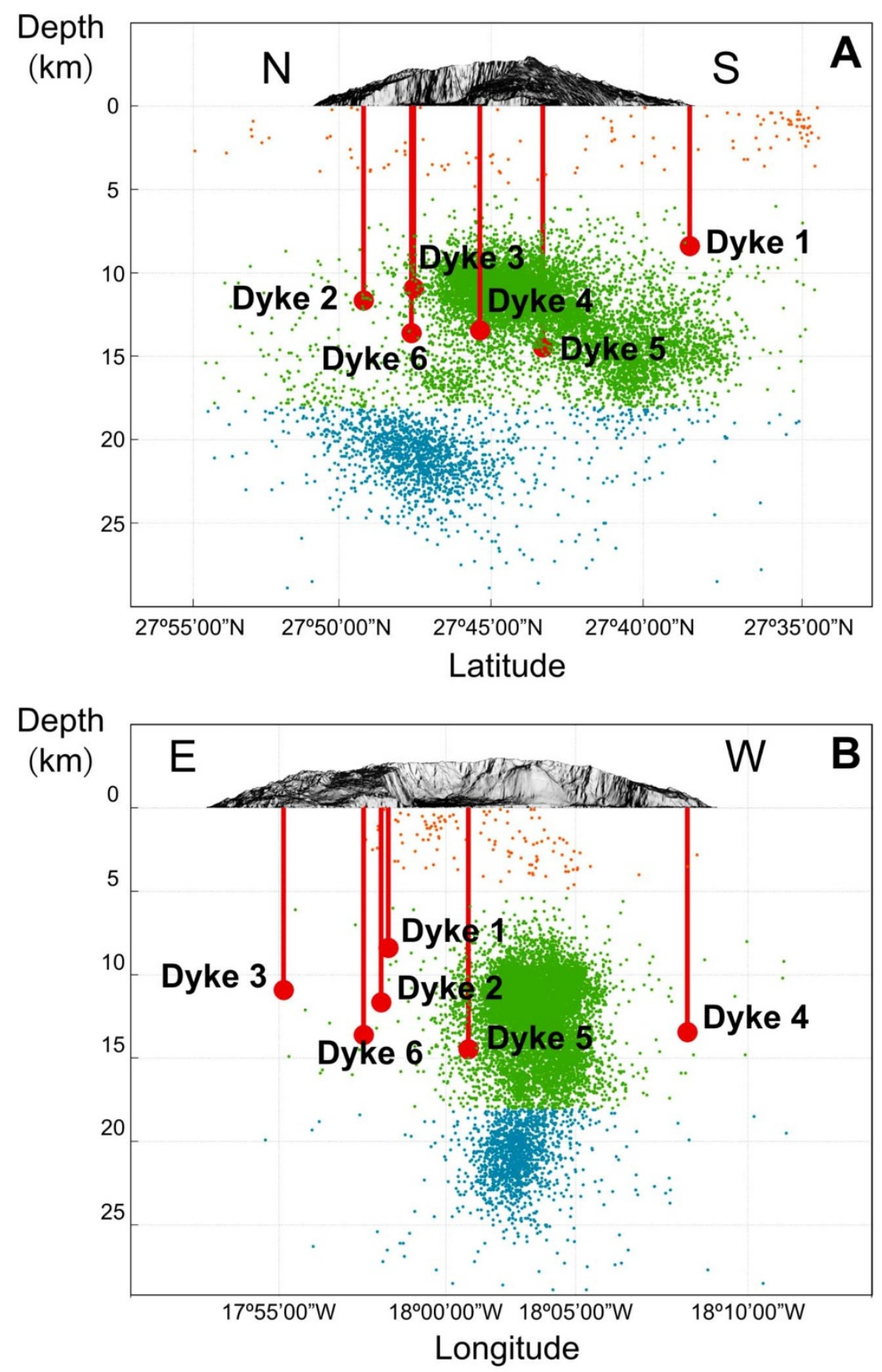

Figure $2 \mid$ Vertical cross-sections through the island of El Hierro oriented parallel (A) and perpendicular (B) to the seismic swarm, indicted by hypocentres (see Fig. 1 for legend). Also shown are the six feeder-dykes (D1-D6), as red lines, and their calculated depths of origin (depths to the source magma chamber) as red dots. Data on hypocenters, registered from 19 July 2011 to 5 March 2012, are open-source data from the IGN Seismic Catalogue, the address of the webpage being: http://www.ign.es/ign/layoutIn/volcaFormularioCatalogo.do (cf. ref. 36). Map composed in ESRI ArcGIS 9.3.1. 
The results indicate that when the length/thickness ratios of feeder-dykes or the length/opening ratios of volcanic fissures, or both, can be calculated, the depth to the associated source magma chamber can be estimated. These estimates offer new constraints on the depths of the magma chambers and can be compared with other estimates, such as from the inversion of geodetic data, earthquake foci, and geochemical and petrological studies. The method is quite general and can be used worldwide wherever there are feeder-dykes/volcanic fissures for which the aspect ratios can be measured.

\section{Discussion}

With modern GPS and InSAR techniques, the opening displacements (and lengths) of volcanic fissures can generally be determined quite accurately ${ }^{1,2}$. Where feeder-dykes can be measured and dated in an active volcano, it is also possible to detect those major long-term changes that may have occurred in the location of the source magma chamber. This offers the possibility of using the present method to trace the spatial evolution of the source magma chamber of an active volcano.

Geodetic and seismic methods for determining the locations of magma chambers in volcanoes are very recent. The first systematic use of the simplest of these methods dates back to the 1950s with the introduction of the nucleus-of-strain or 'Mogi model' for inferring magma-chamber depths from surface deformation ${ }^{1,2}$. Modern GPS and InSAR methods are only a few decades old ${ }^{1-3,23,24}$. The depths to magma chambers obtained from the length-opening ratios of volcanic fissures using geodetic measurements can thus trace the spatial evolution of the magma chamber for, at most, several decades. That time window is normally far too short to show any significant changes in the location of the chamber. However, for many wellmonitored volcanoes that have had frequent fissure eruptions in this time window, such as Etna in Italy ${ }^{21,22}$ and Piton de la Fournaise in Reunion $^{25}$, the present method makes it possible to estimate the depths to the source chambers. In particular, many volcanoes (such as in El Hierro) are apparently supplied with magma from a double magma chamber, that is, a small shallow chamber that, in turn, is fed by a larger, deeper reservoir ${ }^{26}$. Careful analysis of the location of the volcanic fissures and the composition of the eruptive materials issued should then, in combination with the depth estimates from the aspect ratios of the fissures, allow us to distinguish between the two magma sources.

The present method is currently the only one that makes it possible to trace the long-term spatial evolution of magma chambers in volcanoes. This follows because the method can not only be applied to volcanic fissures, but also to feeder-dykes. Feeder-dykes record the opening and the length of the associated volcanic fissure. Measurements of the thickness and length of a feeder-dyke make it possible, using the present method, to calculate the depth to its source chamber.

The present estimates of the depths to the source chambers of the 2011-2012 eruption in El Hierro, based on the feeder-dyke data and the seismic data, are in agreement with new petrological results ${ }^{27-29}$. These results indicate that two interconnected mafic magma chambers were active during the eruption. Similarly, studies of phenocrysts and basaltic glasses suggest that the main magma storage system beneath El Hierro is at depths of $19-26 \mathrm{~km}^{30}$. As for earlier dyke intrusions, such as may partly or entirely span the ages of the present feeder-dykes, there is clear geophysical evidence for vertical intrusive complexes along the rift zones $^{31}$, as well as for large intrusions at roughly 6-12 km depth beneath the island ${ }^{19,32}$.

As indicated above, feeder-dykes have not been widely reported from active volcanoes. The present results, where six clear feederdykes have been identified in a comparatively small island, indicate that systematic search for feeder-dykes could result in many more being observed. This conclusion is supported by recent studies of dykes in well-exposed caldera walls where many feeder-dykes have been observed ${ }^{7,8,27}$. These dykes can be connected to volcanic fissures at the surface, making it possible to calculate their aspect ratios and infer the depth of origin of the magma.

Most of the feeder-dykes studied here range in age up to about $160 \mathrm{ka}$. The feeder dykes indicate that the chamber that supplied magma during the present eruption in El Hierro may have been at essentially the same location for the past 100-200 ka. Similarly, systematic studies of feeder-dykes in other volcanoes should make it possible to trace the evolution of the associated magma chambers over similar or longer periods, that is, over significant parts of, or the entire history of, the associated volcanoes.

\section{Methods}

The theoretical methods used here derive from, first, elastic fracture mechanics and, second, overpressure estimates for magma-filled fractures. Eq. (1) gives the opening displacement or aperture of a crack as a function of its constant internal fluid overpressure. The equation applies to mode I through cracks, such as feeder-dykes must be, that is, extension fractures that extend from one free surface (here a fluid-filled magma chamber) to another free surface (here the earth's surface). Eq. (1) was initially derived in the context of general fracture mechanics ${ }^{16}$, and is discussed elsewhere in the context of volcanotectonics ${ }^{15}$. The equation assumes the internal fluid overpressure in the dyke to be constant, which is generally a good first approximation when there is limited data available as to the exact aperture/thickness variation $^{14,15,33}$. When the aperture/thickness variation of the fissure/dyke is known, the potential variation in overpressure can be considered ${ }^{14,15}$.

The overpressure estimates (Eq. 2) use the general assumption of the magma density being constant. The density of basaltic magma - the main focus here - is roughly constant in a feeder-dyke until at a shallow depth. Gas expansion in the uppermost few hundred metres of the feeder-dyke may lower the magma density considerably ${ }^{34}$, but the overall average density for many basaltic magmas is similar to that used in the present calculations ${ }^{17}$. The crustal density is also taken as a constant, that is, an average crustal density is used. Crustal density varies with depth - it increases on average. In the present case, there is insufficient data on the crustal layers to take the variation in crustal density into account. This is possible for volcanic areas where more detailed mechanical data on the crustal layers is available. In most case, and in the absence of drilling, the densities of the crustal layers are generalised values for thick units rather than individual layers. In the present calculations, as is common, the average density of all these units combined has been estimated and used to calculate the buoyancy effect on the magma overpressure at the point where the feeder-dyke reaches the surface.

The excess pressure $p_{e}$ in the source magma chamber must be similar to the insitu tensile strength of the host rock at the time of its rupture and dyke formation General theoretical stress analyses sometimes suggest that the chamber could hold magma under excess pressure exceeding the tensile strength - such as in the case of an ideal spherical chamber ${ }^{15}$. However, all chambers are, in detail, somewhat irregular in geometry ${ }^{4}$ and the rupture and dyke injection occur at those locations at the chamber boundary where notches and other irregularities raise (concentrate) the tensile stress until it reaches the local in situ tensile strength. The in situ tensile strength is generally low: most measurements range between 0.5 and $6 \mathrm{MPa}$, with occasional strengths as high as $9 \mathrm{MPa}^{15,35}$. Healing and sealing of fractures, partly through geothermal activity, is more common close to the magma chamber than at the surface. Thus, we use a somewhat higher tensile strength for the host rock of the magma chamber $(2.5 \mathrm{MPa})$ than for the surface of the volcano $(1 \mathrm{MPa})$. The latter value is used as an estimate of the stress difference $\sigma_{\mathrm{d}}$ in Eq. (2) in the surface rocks.

The data on the six feeder-dykes in this paper are, as regards thickness, based on direct field measurements. These are well-exposed dykes so that the thickness can be measured accurately. The lengths of the feeder-dykes, or rather the associated volcanic fissures, are obtained from direct measurements on aerial images. All measurements of this type, both as regards thickness and length, have an estimated error of $5-10 \%$.

1. Dzurisin, D. Volcano deformation: new geodetic monitoring techniques (Springer Verlag, Berlin, 2006).

2. Segall, P. Earthquake and volcano deformation (Princeton University Press, Princeton, 2010).

3. Sturkell, E. et al. Volcano geodesy and magma dynamics in Iceland. J. Volcanol. Geotherm. Res. 150, 14-34 (2006).

4. Gudmundsson, A. Magma chambers: formation, local stresses, excess pressures, and compartments. J. Volcanol. Geotherm. Res. 237-238, 19-41 (2012).

5. Gudmundsson, A. Strengths and strain energies of volcanic edifices: implications for eruptions, collapse calderas, and landslides. Nat. Hazards Earth Syst. Sci. 12, 2241-2258 (2012).

6. Galindo, I. \& Gudmundsson, A. Basaltic feeder-dykes in rift zones: geometry, emplacement, and effusion rates. Nat. Hazards Earth Syst. Sci. 12, 3683-3700 (2012).

7. Geshi, N., Kusumoto, S. \& Gudmundsson, A. Geometric difference between nonfeeders and feeder dikes. Geology 38, 195-198 (2010). 
8. Geshi, N., Kusumoto, S. \& Gudmundsson, A. Effects of mechanical layering of host rocks on dike growth and arrest. J. Volcanol. Geotherm. Res. 223, 74-82 (2012).

9. Marti, J. \& Gudmundsson, A. The Las Cañadas caldera (Tenerife, Canary Islands): an overlapping collapse caldera generated by magma-chamber migration. J. Volcanol. Geotherm. Res. 103, 161-173 (2000).

10. Newhall, C. G. \& Dzurisin, D. Historical unrest of large calderas of the world. U.S. Geol. Surv. Bull. 1855, 1-1108 (1988).

11. Gottsmann, J. \& Marti, J. Caldera volcanism: analysis, modelling and response (Elsevier, Amsterdam, 2008)

12. Cole, J. W., Milner, D. M. \& Spinks, K. D. Calderas and caldera structures: a review. Earth Sci. Rev. 69, 1-26 (2005).

13. Guillou, H., Carracedo, J. C., Torrado, F. J. \& Badiola, E. R. K-Ar ages and magnetic stratigraphy of a hotspot-induced, fast grown oceanic island: El Hierro, Canary Islands. J. Volcanol. Geotherm. Res. 73, 141-155 (1996).

14. Kusumoto, S., Gudmundsson, A., Simmenes, T. H., Geshi, N. \& Philipp, S. L. Inverse modeling for estimating fluid-overpressure distributions and stress intensity factors from an arbitrary open-fracture geometry. J. Struct. Geol. 46, 92-98 (2013).

15. Gudmundsson, A. Rock fractures in geological processes (Cambridge University Press, Cambridge, 2011).

16. Sneddon, I. \& Lowengrub, M. Crack problems in the classical theory of elasticity (Wiley, New York, 1969).

17. Murase, T. \& McBirney, A. Properties of some common igneous rocks and their melts at high temperatures. Geol. Soc. Am. Bull. 84, 3563-3592 (1973)

18. Bosshard, E. \& Macfarlane, D. J. Crustal structure of the western Canary Islands from seismic refraction and gravity data. J. Geophys. Res. 75, 4901-4918 (1970).

19. Montesinos, F. G., Arnoso, J., Benavent, M. \& Vieira, R. The crustal structure of El Hierro (Canary Islands) from 3-D gravity inversion. J. Volcanol. Geotherm. Res. 150, 283-299 (2006).

20. Gudmundsson, A. Effect of tensile stress concentration around magma chambers on intrusion and extrusion frequencies. J. Volcanol. Geotherm. Res. 35, 179-194 (1988)

21. Alosi, M., Bonaccorso, A. \& Gambino, S. Imaging composite dike propagation (Etna, 2002 case). J. Geophys. Res. 111, dx.doi.org/10.1029/2005JB003908 (2006).

22. Neri, M. et al. Structural analysis of the eruptive fissures at Mount Etna (Italy). Ann. Geophys. 54, 464-479 (2011).

23. Massonnet, D. et al. The displacement field of the Landers earthquake mapped by radar interferometry. Nature 364, 138-142 (1993).

24. Burgmann, R., Rosen, P. A. \& Fielding, E. J. Synthetic aperture radar interferometry to measure Earth's surface topography and deformation. Annu. Rev. Earth Planet. Sci. 28, 169-209 (2000).

25. Lenat, J. F., Bachelery, P. \& Merle, O. Anatomy of Piton de la Fournaise volcano (La Reunion, Indian Ocean). Bull. Volcanol. 74, 1945-1961 (2012).

26. Gudmundsson, A. How local stresses control magma-chamber ruptures, dyke injections, and eruptions in composite volcanoes. Earth Sci. Rev. 79, 1-31 (2006).

27. Martí, J. et al. Causes and mechanisms of the 2011-2012 El Hierro (Canary Islands) submarine eruption. J. Geophys. Res. 118, dx.doi.org/10.1002/jgrb.50087 (2013)

28. Martí, J. et al. Correlation of magma evolution and geophysical monitoring during the 2011-2012 El Hierro (Canary Islands) submarine eruption. J. Petrology dx.doi.org/10.1093/petrology/egt014 (2013).
29. Meletlidis, S. et al. Xenopumices from the 2011-2012 submarine eruption of El Hierro (Canary Islands, Spain): constraints on the plumbing system and magma ascent. Geophys. Res. Lett. 39, L17302, dx.doi.org/10.1029/2012GL052675 (2012).

30. Stroncik, A., Klügel \& Hansteen, T. H. The magmatic plumbing system beneath El Hierro (Canary Islands): constraints from phenocrysts and naturally quenched basaltic glasses in submarine rocks. Contr. Mineral. Petrol. 157, 593-607 (2009).

31. Blanco-Montenegro, I., Nicolosi, I., Pignatelli, A. \& Chiappini, M. Magnetic imaging of the feeding system of oceanic volcanic islands: El Hierro (Canary Islands). Geophys. J. Int. 173, 339-350 (2008).

32. Montesinos, F. G., Arnoso, J. \& Benavent, M. New study of the local gravity field of El Hierro (Canary Islands). Física de la Tierra 17, 113-127 (2005).

33. Kusumoto, S., Geshi, N. \& Gudmundsson, A. Aspect ratios and magma overpressures of non-feeder dikes observed in the Miyake-jima volcano (Japan), and fracture toughness of its upper part. Geophys. Res. Lett. 40, 1-5, dx.doi.org/ 10.1002/grl.50284 (2013)

34. Greenland, L. P., Okamura, A. T. \& Stokes, J. B. Constraints on the mechanics of the eruption. In: Wolfe, W. (Ed.), The Puu Oo eruption of Kilauea volcano, Hawaii: episodes 1 through 20, January 3, 1983, through June 8, 1984.U.S. Geol. Surv. Prof. Pap. 1463, 155-166 (1988).

35. Amadei, B. \& Stephansson, O. Rock stress and its measurement (Chapman \& Hall, London, 1997).

36. López, C. et al. Monitoring the volcanic unrest of El Hierro (Canary Islands) before the onset of the 2011-2012 submarine eruption. Geophys. Res. Lett. 39, L13303, dx.doi.org/10.1029/2012GL051846 (2012).

\section{Acknowledgements}

We thank an anonymous reviewer and the Editor, Jeremy Richards, for very helpful comments. This work was mainly funded by the Spanish Geological Survey (IGME) through the MODEX Project (directed by Luis Laín) and a Research Grant for LB. We would like to thank to the "Consejo Insular de Aguas de El Hierro" (Cabildo Insular de El Hierro) for their support.

\section{Author contributions}

Field measurements of feeder-dykes and volcanic fissures were made by L.B. and I.G. Data analysis and illustrations were mainly made by L.B., I.G. and J.M.M. The manuscript was primarily written by A.G. with input from L.B. and I.G.

\section{Additional information}

Competing financial interests: The authors declare no competing financial interests.

How to cite this article: Becerril, L., Galindo, I., Gudmundsson, A. \& Morales, J.M. Depth of origin of magma in eruptions. Sci. Rep. 3, 2762; DOI:10.1038/srep02762 (2013).

This work is licensed under a Creative Commons AttributionNonCommercial-NoDerivs 3.0 Unported license. To view a copy of this license, visit http://creativecommons.org/licenses/by-nc-nd/3.0 